\title{
Clinical Significance of Thrombosis in an Intracardiac Blind Pouch After a Fontan Operation
}

\author{
Sang Yun Lee $\cdot$ Jae Suk Baek $\cdot$ Gi Beom Kim $\cdot$ Bo Sang Kwon • \\ Eun Jung Bae $\cdot$ Chung II Noh $\cdot$ Jung Yun Choi $\cdot$ Hong Kuk Lim $\cdot$ \\ Woong Han Kim $\cdot$ Jeong Ryul Lee $\cdot$ Yong Jin Kim
}

Received: 20 February 2011/ Accepted: 13 July 2011/Published online: 5 August 2011

(C) The Author(s) 2011. This article is published with open access at Springerlink.com

\begin{abstract}
The univentricular heart after the Fontan operation may have a blind pouch formed by the pulmonary stump or rudimentary ventricle according to the anatomy before surgery. Thrombosis in an intracardiac blind pouch of patients with a univentricular heart is a hazardous complication. Because only a few reports have described this complication, the authors evaluated the clinical significance of thrombosis in an intracardiac blind pouch of a univentricular heart. They performed a retrospective review of medical records from August 1986 to December 2007. Four patients were confirmed as having thrombosis in a pulmonary artery stump and one patient as having thrombosis in a rudimentary ventricle shown by cardiac computed tomography (CT). This represents $1.85 \%$ $(5 / 271)$ of patients with ongoing regular follow-up evaluation after the Fontan operation. The median age at diagnosis was 14.2 years. Two of the five patients were taking aspirin and one patient was taking warfarin when they were identified for the development of thrombosis. None of the patients demonstrated thrombosis in the Fontan tract or venous side of the circulation. Brain magnetic resonance imaging (MRI) showed that three patients had cerebral infarction and one patient had suggestive old ischemia. Three patients with thrombus in the pulmonary stump
\end{abstract}

S. Y. Lee · J. S. Baek · G. B. Kim (ه) .

B. S. Kwon - E. J. Bae · C. I. Noh · J. Y. Choi

Department of Pediatrics, Seoul National University Children's

Hospital, 101 Daehang-Ro, Jongno-gu, Seoul 110-744, South

Korea

e-mail: ped9526@snu.ac.kr

H. K. Lim - W. H. Kim · J. R. Lee - Y. J. Kim

Department of Thoracic and Cardiovascular Surgery,

Seoul National University Children's Hospital,

101 Daehang-Ro, Jongno-gu, Seoul 110-744, South Korea underwent pulmonary artery stump thrombectomy and pulmonary valve obliteration. One patient with thrombus in the rudimentary ventricle underwent ventricular septal defect (VSD) closure with thrombectomy. Thrombus in a blind pouch could cause systemic thromboembolism despite little blood communication. Therefore, surgical modification of the pulmonary stump and VSD closure of the rudimentary ventricle are required to reduce the risk of later thrombus formation. Clinicians should not overlook the possibility of thrombus in a ligated pulmonary artery stump or a rudimentary ventricle after the Fontan operation, which may increase the risk of embolic stroke for patients with single-ventricle physiology.

Keywords Echocardiography · Fontan - Stroke · Thrombosis

Since its initial introduction in 1971, the Fontan procedure has undergone multiple modifications [6, 19] aimed at directing the systemic venous return directly to the pulmonary artery (PA) [10]. Subsequently, in several cases, various surgical mortality rates associated with diverse approaches have been reported $[1,11,15,16]$.

Fontan physiology has been called paradoxical because systemic venous hypertension is imposed with concomitant PA hypotension [5]. This hemodynamic compromise underlies several late complications including arrhythmia, heart failure, thromboembolism, hepatic dysfunction, protein-losing enteropathy, and worsening cyanosis $[12,13]$.

Among these complications, intracardiac thrombus formation is serious and can be fatal because of thromboembolism to vital distal organs. Although thrombosis has been reported to occur in a variety of locations $[4,24]$, few reports describe thrombosis in an intracardiac blind pouch, 
including a ligated main pulmonary stump or a rudimentary ventricle, and its risk for cerebrovascular embolic events.

Recently, we experienced several cases of thrombosis in an intracardiac blind pouch, resulting in thrombectomy. This study aimed to evaluate the clinical significance of thrombosis in an intracardiac blind pouch after the Fontan operation on a univentricular heart.

\section{Materials and Methods}

We retrospectively reviewed the medical records of all patients who had undergone the Fontan operation with ongoing follow-up evaluation from August 1986 to December 2007 at the Seoul National University Children's Hospital. At our institution, all the patients who underwent palliated single-ventricle physiology were routinely screened by transthoracic echocardiography (TTE) for thrombosis in the systemic circulation, including a ligated main pulmonary stump or a rudimentary ventricle. The TTE was performed with the Acuson Sequoia C256 (Siemens Company, Mountain View, CA, USA) or the GE Vivid 7 scanner (GE Vingmed Ultrasound, Horten, Norway) used by an experienced pediatric cardiologist according to a standardized protocol. This study protocol was approved by our Institutional Review Board, which waived the patient consent because of the retrospective data analysis.

Cardiac computed tomography (CT) was performed for 142 of 271 patients with ongoing follow-up evaluation after the Fontan operation to assess for cardiac, pulmonary, hepatic, or other complications. Because CT imaging is useful for identifying structural anomalies or relations, it was performed for patients with suspected pulmonary arterial anomalies, intracardiac thrombus as noted by echocardiography, airway problems such as plastic bronchitis, and liver mass or cirrhosis. On the other hand, CT was not performed routinely for all Fontan patients.

The study acquired CT data using a multidetector CT scanner (Sensation 64; Siemens Medical Systems,
Forchheim, Germany) with a 32-row detector collimation that obtained $64 \times 0.6-\mathrm{mm}$ slices by applying the $z$-axis flying-focus technique, a table translations speed of $3.8 \mathrm{~mm}$ per rotation, and a gantry rotation time of $0.33 \mathrm{~s}$. In all patients, nonionic contrast medium (Ultravist; Schering, Erlangen, Germany) was injected for vascular enhancement. A thrombus was defined as a "hypodense" lesion. The CT density (in Hounsfield Units) was measured within multiple regions of interest (ROIs) on axial images.

We identified five patients with thrombi in an intracardiac blind pouch after a Fontan operation. We also performed brain magnetic resonance imaging (MRI) if the patients showed neurologic symptoms such as periodic headache, behavioral change, seizure, sensory change, or motor weakness. An MRI was acquired for all patients with identified thrombi using a circularly polarized head coil in a conventional 1.5-T whole-body imaging system (Magnetom Vision, Siemens Medical Systems, Iselin, NJ). In addition, we reviewed medical records concerning the first palliative operation, types of Fontan operation, age at the time of diagnosis, methods of antithrombotic medication, presence of neurologic complications, treatment methods, and final outcomes for thrombosis.

\section{Results}

\section{Patient Characteristics}

The clinical characteristics of the patients are described in Table 1. For five patients, thrombi in an intracardiac blind pouch was identified by TTE and cardiac CT. This comprised 1.85\% (5/271) of the patients with ongoing regular follow-up evaluation after a Fontan operation. All the patients were male. The median age of the patients at the time of this study was 17.2 years (range, 7.0-17.8 years), and the median age at the diagnosis of thrombus in the systemic circulation was 14.2 years (range, 0.6-15.4 years). Four of the five patients experienced thrombi in the

Table 1 Clinical characteristics of the patients

\begin{tabular}{|c|c|c|c|c|c|c|c|c|c|c|}
\hline Patient & $\begin{array}{l}\text { First } \\
\text { operation }\end{array}$ & $\begin{array}{l}\text { Fontan } \\
\text { type }\end{array}$ & $\begin{array}{l}\text { Age at } \\
\text { diagnosis } \\
\text { (years) }\end{array}$ & $\begin{array}{l}\text { Time from } \\
\text { PA ligation } \\
\text { (years) }\end{array}$ & $\begin{array}{l}\text { Pre-Dx } \\
\text { drug }\end{array}$ & $\begin{array}{l}\text { Post-Dx } \\
\text { drug }\end{array}$ & $\begin{array}{l}\text { Neurologic } \\
\text { complication }\end{array}$ & $\begin{array}{l}\text { Brain } \\
\text { MRI }\end{array}$ & Thrombectomy & Echocardiography \\
\hline 1 & PAB & ECC & 4.8 & 2 & Aspirin & Warfarin & - & - & + & + \\
\hline 2 & RMBTS & LT & 15.5 & 12.2 & - & Warfarin & $\begin{array}{c}\text { Seizure, } \\
\text { palsy }\end{array}$ & Infarct & + & + \\
\hline 3 & PAB & ECC & 0.6 & 0.1 & - & Warfarin & Hemiparesis & Infarct & - & + \\
\hline 4 & BCPS & LT & 14.2 & 11.1 & Aspirin & Aspirin & - & Ischemia & + & + \\
\hline 5 & BCPS & LT & 15.4 & 14.5 & Warfarin & Warfarin & Syncope & Infarct & + & + \\
\hline
\end{tabular}

$P A$ pulmonary artery; $D x$ diagnosis; $M R I$ magnetic resonance imaging; $P A B$ pulmonary artery banding; ECC extracardiac conduit; $R M B T S$ right modified Blalock-Taussig shunt; $L T$ lateral tunnel; $B C P S$ bidirectional cavopulmonary shunt 


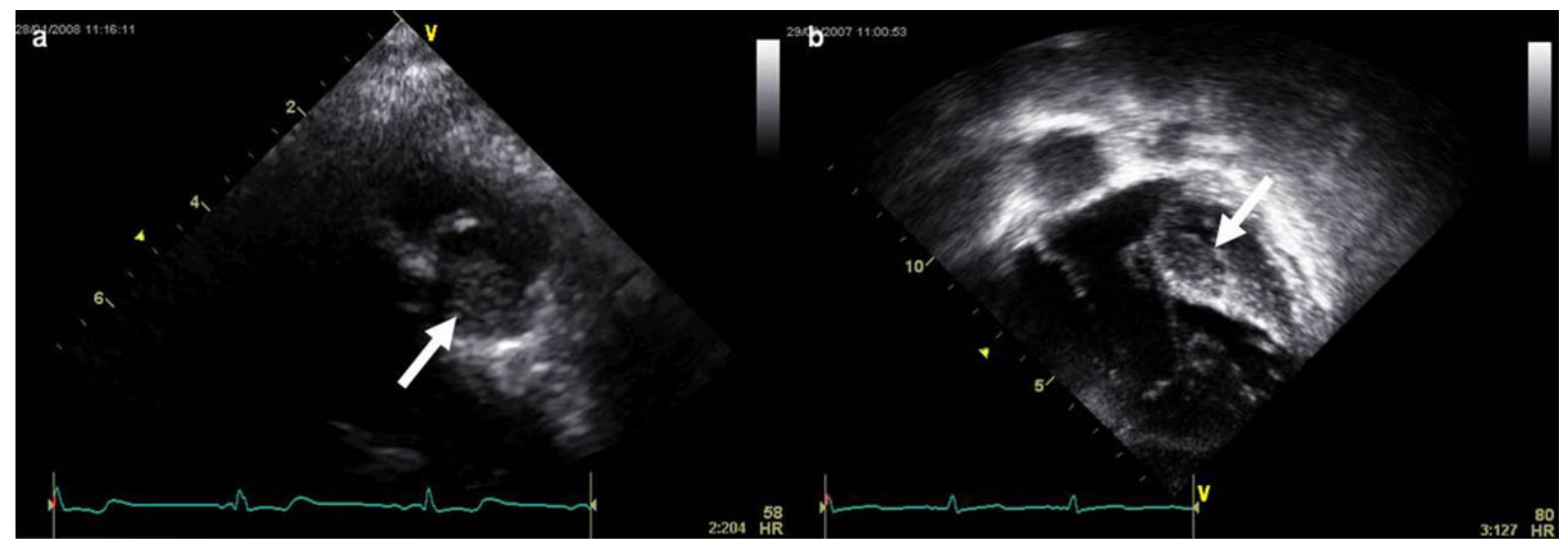

Fig. 1 Thrombus in an intracardiac blind pouch after the Fontan operation shown by transthoracic echocardiography. a Thrombus in the main pulmonary artery stump (patient 2 ). b Thrombus in the rudimentary ventricle (patient 5 )

ligated main PA stump. The remaining patient had a thrombus in the rudimentary ventricle (Fig. 1).

As a first palliative operation, two patients underwent PA banding. One patient received a Blalock-Taussig shunt, and two patients received a bidirectional cavopulmonary shunt. Fontan operations were performed at a median age of 2.84 years (range, 1.1-3.75 years). Among the types of Fontan operation, two patients had surgery using an extracardiac conduit, and three patients underwent surgery by the lateral tunnel method. Before the diagnosis of thrombus, two patients had taken aspirin, one patient had taken warfarin, and two patients had not have taken any antithrombotic medication. Two patients had mild liver cirrhosis shown by abdomen CT but did not have significant coagulopathy. Therefore, no patient had protein $\mathrm{S}$ or $\mathrm{C}$ deficiency.

\section{Neurologic Complications and Treatments}

Four patients showed brain infarct or ischemia on brain MRI. Three of the four patients had neurologic symptoms including seizure and right-side palsy in patient 2 , left hemiparesis in patient 3 , and syncope in patient 5 (Table 1).

Patient 2, who had tricuspid atresia type $1 \mathrm{~b}$, underwent a fenestrated lateral tunnel Fontan operation at the age of 3 years. At 2 years after PA ligation, the patient experienced partial seizure and right-side palsy, which resolved after anticoagulation treatment. Partial seizure developed subsequently and occurred three additional times.

When the patient was 16 years old, routine TTE showed thrombus in the ligated main PA stump, which was confirmed by cardiac CT. Brain MRI showed multifocal T2 high-signal intensity nodules in the left thalamus and periventricular white matter and cerebellum, which represented old cerebral infarctions due to thromboembolism (Fig. 2a).

Although we did not know whether the cause of recurrent neurologic complication was fenestration of the Fontan pathway or not, the blind pouch of the main PA stump could have been a nest of thrombus formation. The patient underwent thrombectomy in the main PA stump and pulmonary valve obliteration. At this writing, he is receiving warfarin as an antithrombotic agent after thrombectomy.

Patient 3, who had a double-outlet right ventricle and double-inlet right ventricle, underwent the Fontan operation with an extracardiac conduit at the age of 32 months. At the age of 30 months, the patient experienced right-side lip deviation and left-side weakness in the extremities. Brain MRI showed an acute infarction in the right middle cerebral artery territory (Fig. 2b). All symptoms resolved with subcutaneous injection of low-molecular-weight heparin and subsequent warfarin medication. However, cardiac CT identified thrombus in the main PA stump at the time of treatment that was not seen at the time of the Fontan operation.

Patient 4, who had an unbalanced atrioventricular septal defect with pulmonary stenosis, underwent a lateral tunnel Fontan operation at the age of 4 years. Routine TTE showed thrombus in the ligated main PA stump when the patient was 14 years old, which was confirmed by cardiac CT. The patient did not show any neurologic symptoms, but brain MRI showed a few T2 high-signal lesions in both paraventricular white matters reflecting old cerebral infarctions (Fig. 2c). Although he did not have any neurologic symptoms, we performed thrombectomy in the main PA stump and pulmonary valve obliteration because of blood flow communication through the pulmonary valve and concern about systemic embolization from a thrombus in the PA stump. At this writing, he is receiving aspirin as an antithrombotic agent. 
Fig. 2 Neurologic

complications shown by brain magnetic resonance imaging $(M R I)$. a Focal T2 high-signal intensity nodules in the left thalamus suggesting old infarction (patient 2). b Gyral edema and swelling in the right middle cerebral artery territory suggesting cerebral infarction (patient 3). c A few T2 highsignal enhanced lesions in right periventricular white matter suggesting old ischemia (patient 4). d Focal T2 highsignal intensity in left basal ganglia and inferior temporal lobe suggesting old ischemia (patient 5)
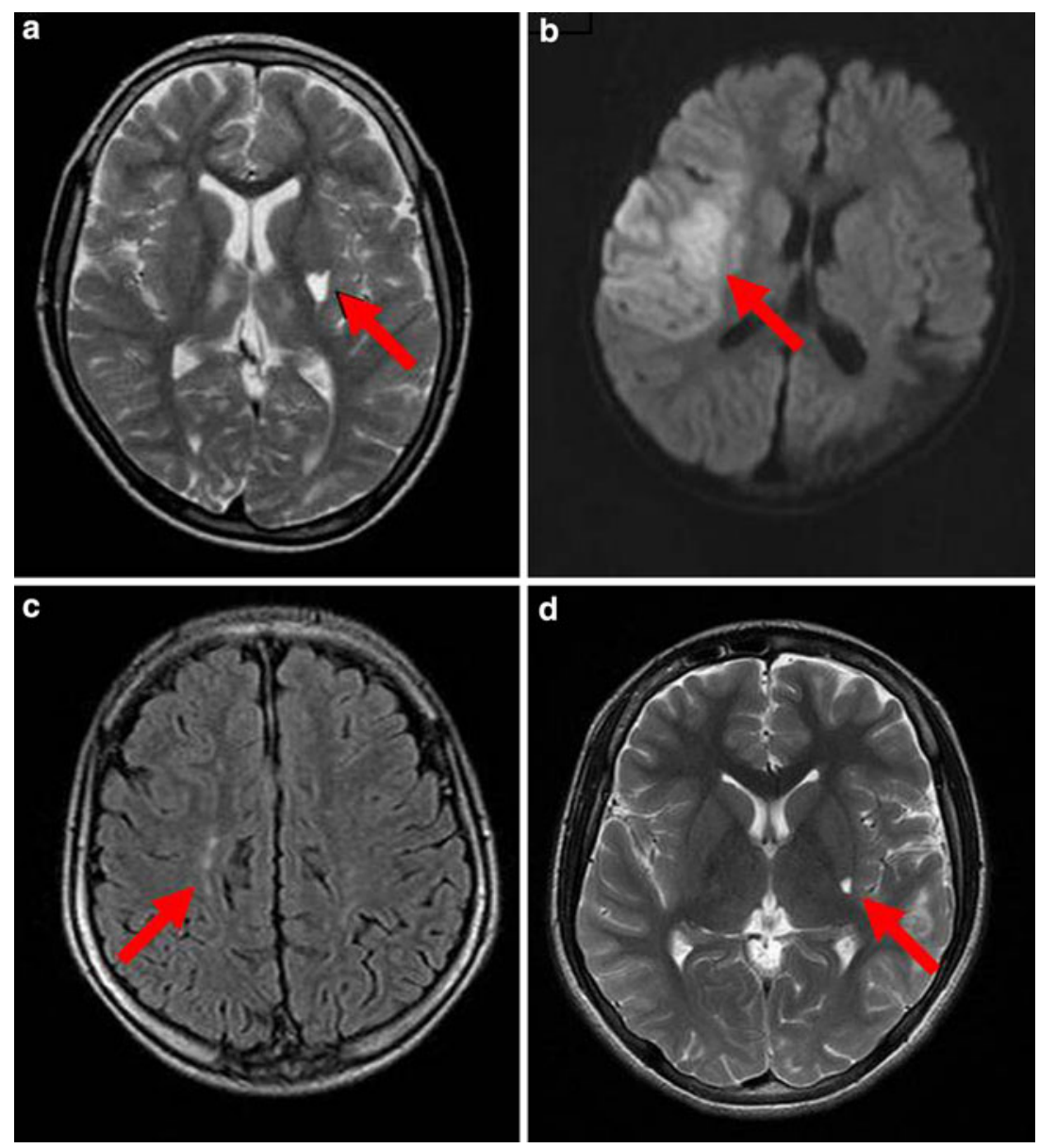

Patient 5, who had a double-outlet right ventricle with a hypoplastic left ventricle ( $\mathrm{LV})$, underwent a lateral tunnel Fontan operation at the age of 3 years. At the age of 7 years, he experienced syncope, motor weakness, and vomiting. Brain MRI showed a cerebral infarction in the temporo-occipital area (Fig. 2d), and a thrombus in a rudimentary LV was identified on TTE. All symptoms and thrombus disappeared after anticoagulation therapy. However, routine TTE at the age of 15 years showed the reappearance of thrombotic materials in the rudimentary $\mathrm{LV}$, and a cardiac CT confirmed the thrombus in the rudimentary LV (Fig. 1b). This occurred despite continuous medication with warfarin. Closure of the residual ventricular septal defect (VSD) and thrombectomy were performed.

Discrepancy in the Diagnosis of Thrombus Between Cardiac CT and TTE

Three patients in our study showed thrombi in the main PA stump and a rudimentary ventricle on the cardiac CT performed for atypical symptoms and pulmonary problems.
However, we could not visualize thrombus by repeat TTE. For one of them, TTE and LV angiography by contrastmedia injection were performed, but we could not identify a significant thrombus in the systemic circulation, in contrast to the cardiac CT (Fig. 3). We did not perform any treatment for the thrombus shadow in the cardiac CT because the patients did not exhibit any neurologic symptoms, and repeated TTE did not show a thrombotic shadow at all. At this writing, the patients all are being closely followed.

\section{Discussion}

Many complications may occur late after the Fontan procedure including thromboembolism, heart failure, sepsis, and other problems [12, 18, 26]. Thrombus formation is considered a significant cause for morbidity and mortality [4, 12]. Thromboembolism after a Fontan operation has been variously attributed to low flow states, stasis in the venous pathways, right-to-left shunts, blind cul-de-sacs, prosthetic materials, atrial arrhythmias, and hypercoagulable states [2, 12, 25]. 


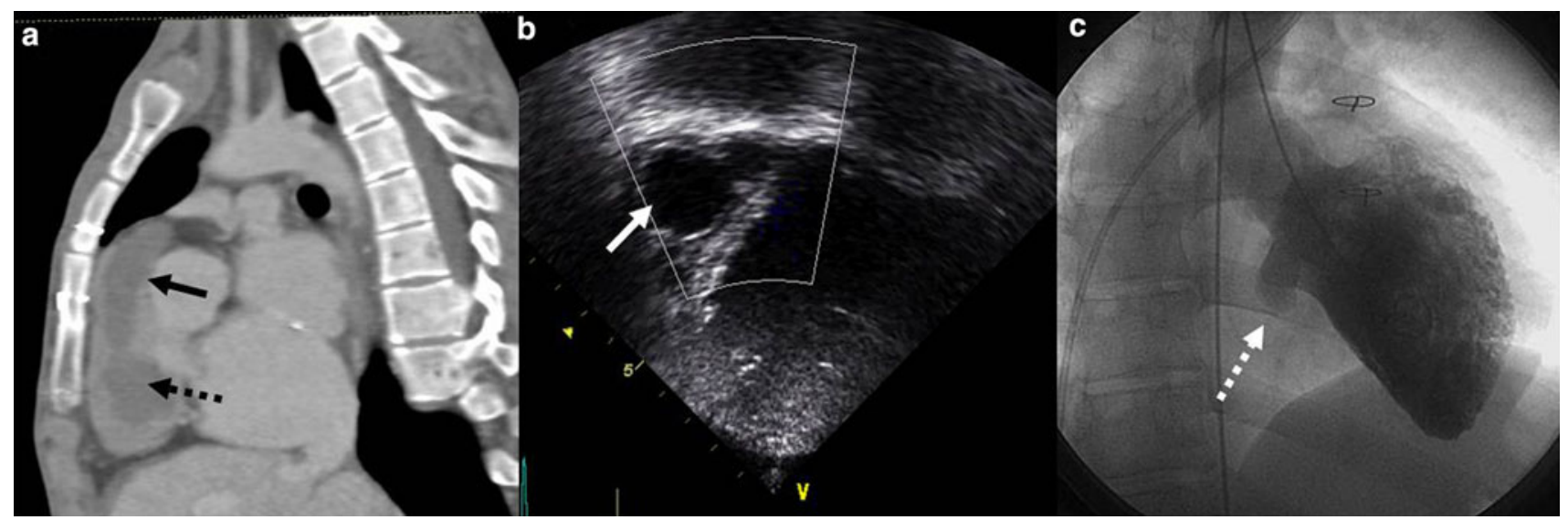

Fig. 3 Discrepancy in the diagnosis of thrombus between cardiac computed tomography $(C T)$ and transthoracic echocardiography in one patient. a Cardiac CT showing a thrombus shadow in the main pulmonary artery (PA) stump and the rudimentary ventricle.

Intracardiac thrombus formation can lead to pulmonary thromboembolic disease if it occurs within the Fontan circuit, whereas cerebral stroke and infarct develop if the former type of thrombus crosses a Fontan fenestration or if the thrombus forms within left heart structures [4]. Leftsided embolism could lead to neurologic deficit, organ dysfunction, or death [7]. Therefore, thrombus in the systemic circulation (left-sided embolism) is a more serious condition that should be treated urgently. Three of the five patients in this study had neurologic complications that required an immediate response.

Several studies have reported the prevalence of intracardiac thrombus development to be $3-33 \%$ [4, 13, 22, 24]. In many studies, the predisposing factors for intracardiac thrombosis included hepatic dysfunction, protein-losing enteropathy, and arrhythmia. Generally, patients after the Fontan operation show a hypercoagulable state caused by deficiencies in protein $\mathrm{S}$, protein $\mathrm{C}$, factor 7 , and antithrombin 3. Deficiencies of coagulation factor may relate to decreased hepatic function and enteric losses.

In 2001, Coon et al. [4] reported that the curve of thrombus formation very closely mimics the previously published curves for the development of arrhythmia and protein-losing enteropathy after a Fontan operation [3, 8]. These findings suggest the co-dependent relation between thrombus formation and other late complications.

Thrombosis in the systemic circulation of the univentricular heart has not been reported frequently $[17,20,21$, 27]. Formation of a blind pouch after the Fontan operation in patients with single-ventricle physiology is not unusual. Flow patterns suggest that there is some inflow to the culde-sac and that small regurgitated jets emanating from the valve leaflets may be observed. Because the only outlet from these hearts is the aorta, the thrombus will enter the systemic circulation if it dislodges. Another cul-de-sac in b Transthoracic echocardiography showing no thrombus shadow in the rudimentary ventricle. c Main ventriculogram showing no communication between the main ventricle and the rudimentary ventricle

patients who undergo the Fontan operation is a rudimentary ventricle, in which a thrombus could be formed.

There are surgical methods for decreasing the risk of embolic events. One method is an excision of the pulmonary valve leaflets at the time of the bidirectional cavopulmonary shunt or Fontan procedure, when the PA is ligated. With this approach, the proximal stump widely communicates with the ventricular chamber without stasis of blood.

Another approach involves oversewing of the leaflets, which eliminates the communication between the proximal PA stump and the systemic ventricle. However, oversewing of valve leaflets in an infant with more delicate valve tissue may not be feasible. Also, for prevention of thrombosis in the rudimentary ventricle, widening or closure of communication between the main and rudimentary ventricle is required when the bidirectional cavopulmonary shunt or the Fontan procedure is performed. Then, the rudimentary ventricle must be followed carefully by routine echocardiography.

Because thrombus formation in patients after the Fontan operation is a major complication, accurate diagnosis of the thrombosis by means of an imaging study is the first step for optimal treatment. In clinical practice, echocardiography for the diagnosis of intracardiac thrombus has a low sensitivity and a high specificity [23]. Generally, TTE has an overall sensitivity of $20-30 \%$ and a specificity exceeding 95\%, whereas transesophageal echocardiography has an overall sensitivity of $30-40 \%$ and a specificity exceeding 95\%. On the other hand, cardiac CT has high sensitivity and specificity and a low positive predictive value [9]. Generally, the positive predictive value of cardiac CT for intracardiac thrombus is less than $40 \%$.

These false-positive findings may be explained by spontaneous sluggish echo contrasts in Fontan patients. Early CT data acquisition during the arterial phase and 
filling defects in cul-de-sacs could be causes of a misdiagnosed thrombosis in the atrial appendage, pulmonary stump, or rudimentary ventricle [14]. In this regard, for three other patients in our study, thrombus of the systemic circulation was diagnosed based on false-positive results from cardiac CT. The positive findings from cardiac CT that do not meet clinical conditions must be evaluated by another diagnostic method.

Differentiating the thrombus from a fibrosis or scar can be quite challenging with echocardiography and cardiac CT. Cardiac MRI, by using delayed enhancement imaging, may help to diagnose thrombus formation better in such patients.

How to protect patients from the occurrence of thrombosis after the Fontan operation remains unclear, particularly considering our findings of thrombus formation even in patients receiving aspirin or warfarin. Therefore, prospective trials to determine the potential benefits or risks of routine anticoagulation for all children after the Fontan operation are warranted.

In conclusion, we should not overlook the possibility of thrombus in a ligated PA stump or a rudimentary ventricle after the Fontan operation, which may increase the risk of embolic stroke in patients with a single-ventricle physiology. Empirical modifications of the PA stump and rudimentary ventricle to reduce the risk of later thrombus formation must be attempted. Aggressive thrombectomy for patients with thrombosis of the proximal PA stump and rudimentary ventricle should be considered to prevent neurologic complications. Thrombi identified by cardiac CT should be considered carefully in the diagnosis and treatment due to the low predictive rate.

Open Access This article is distributed under the terms of the Creative Commons Attribution Noncommercial License which permits any noncommercial use, distribution, and reproduction in any medium, provided the original author(s) and source are credited.

\section{References}

1. Alphonso N, Baghai M, Sundar P, Tulloh R, Austin C, Anderson D (2005) Intermediate-term outcome following the Fontan operation: a survival, functional, and risk-factor analysis. Eur J Cardiothorac Surg 28:529-535

2. Cheung YF, Chay GW, Chiu CS, Cheng LC (2005) Long-term anticoagulation therapy and thromboembolic complications after the Fontan procedure. Int J Cardiol 102:509-513

3. Cohen MI, Wernovsky G, Vetter VL, Wieand TS, Gaynor JW, Jacobs ML, Spray TL, Rhodes LA (1998) Sinus node function after a systematically staged Fontan procedure. Circulation 98(19 Suppl):II352-358; discussion II358-III359

4. Coon PD, Rychik J, Novello RT, Ro PS, Gaynor JW, Spray TL (2001) Thrombus formation after the Fontan operation. Ann Thorac Surg 71:1990-1994

5. de Leval MR (2005) The Fontan circulation: a challenge to William Harvey? Nat Clin Pract Cardiovasc Med 2:202-208
6. de Leval MR, Kilner P, Gewillig M, Bull C (1988) Total cavopulmonary connection: a logical alternative to atriopulmonary connection for complex Fontan operations: experimental studies and early clinical experience. J Thorac Cardiovasc Surg 96: 682-695

7. du Plessis AJ, Chang AC, Wessel DL, Lock JE, Wernovsky G, Newburger JW, Mayer JE Jr (1995) Cerebrovascular accidents following the Fontan operation. Pediatr Neurol 12:230-236

8. Feldt RH, Driscoll DJ, Offord KP, Cha RH, Perrault J, Schaff HV, Puga FJ, Danielson GK (1996) Protein-losing enteropathy after the Fontan operation. J Thorac Cardiovasc Surg 112:672680

9. Feuchtner GM, Dichtl W, Bonatti JO, Jodocy D, Muller S, Hintringer F, Gradl J, Klauser A, Cury RC (2008) Diagnostic accuracy of cardiac 64-slice computed tomography in detecting atrial thrombi: comparative study with transesophageal echocardiography and cardiac surgery. Invest Radiol 43:794-801

10. Fontan F, Baudet E (1971) Surgical repair of tricuspid atresia. Thorax 26:240-248

11. Giannico S, Hammad F, Amodeo A, Michielon G, Drago F, Turchetta A, Di Donato R, Sanders SP (2006) Clinical outcome of 193 extracardiac Fontan patients: the first 15 years. J Am Coll Cardiol 47:2065-2073

12. Khairy P, Poirier N, Mercier LA (2007) Univentricular heart. Circulation 115:800-812

13. Khairy P, Fernandes SM, Mayer JE Jr, Triedman JK, Walsh EP, Lock JE, Landzberg MJ (2008) Long-term survival, modes of death, and predictors of mortality in patients with Fontan surgery. Circulation 117:85-92

14. Kim DH, Choi SI, Choi JA, Chang HJ, Choi DJ, Lim C, Cho JH, Park JH (2006) Various findings of cardiac thrombi on MDCT and MRI. J Comput Assist Tomogr 30:572-577

15. Kim SJ, Kim WH, Lim HG, Lee JY (2008) Outcome of 200 patients after an extracardiac Fontan procedure. J Thorac Cardiovasc Surg 136:108-116

16. Knott-Craig CJ, Danielson GK, Schaff HV, Puga FJ, Weaver AL, Driscoll DD (1995) The modified Fontan operation: an analysis of risk factors for early postoperative death or takedown in 702 consecutive patients from one institution. J Thorac Cardiovasc Surg 109:1237-1243

17. Koide M, Abe M, Kodera K, Sudo K, Seguchi M, Sakai A (1999) Thromboembolism originated from the pulmonary artery stump after Fontan operation. Jpn J Thorac Cardiovasc Surg 47:346-349

18. Lee YS, Baek JS, Kwon BS, Kim GB, Bae EJ, Noh CI, Choi JY, Yun YS (2010) Pediatric emergency room presentation of congenital heart disease. Korean Circ J 40:36-41

19. Marcelletti C, Corno A, Giannico S, Marino B (1990) Inferior vena cava-pulmonary artery extracardiac conduit: a new form of right heart bypass. J Thorac Cardiovasc Surg 100:228-232

20. Oski JA, Canter CE, Spray TL, Kan JS, Cameron DE, Murphy AM (1996) Embolic stroke after ligation of the pulmonary artery in patients with functional single ventricle. Am Heart J 132:836-840

21. Rosenthal DN, Bulbul ZR, Friedman AH, Hellenbrand WE, Kleinman CS (1995) Thrombosis of the pulmonary artery stump after distal ligation. J Thorac Cardiovasc Surg 110:1563-1565

22. Shirai LK, Rosenthal DN, Reitz BA, Robbins RC, Dubin AM (1998) Arrhythmias and thromboembolic complications after the extracardiac Fontan operation. J Thorac Cardiovasc Surg 115: 499-505

23. Srichai MB, Junor C, Rodriguez LL, Stillman AE, Grimm RA, Lieber ML, Weaver JA, Smedira NG, White RD (2006) Clinical, imaging, and pathological characteristics of left ventricular thrombus: a comparison of contrast-enhanced magnetic resonance imaging, transthoracic echocardiography, and transesophageal echocardiography with surgical or pathological validation. Am Heart J 152:75-84 
24. Tsang W, Johansson B, Salehian O, Holm J, Webb G, Gatzoulis MA, Therrien J (2007) Intracardiac thrombus in adults with the Fontan circulation. Cardiol Young 17:646-651

25. van Nieuwenhuizen RC, Peters M, Lubbers LJ, Trip MD, Tijssen JG, Mulder BJ (1999) Abnormalities in liver function and coagulation profile following the Fontan procedure. Heart 82: $40-46$
26. Wu MH (2010) Sudden death in pediatric populations. Korean Circ J 40:253-257

27. Yie K, Lee CH, Kim SJ (2008) Thrombi in the main pulmonary artery stump after a Fontan operation. Pediatr Cardiol 29:870-871 